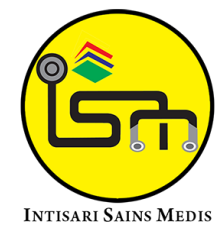

Published by Intisari Sains Medis

\section{Predictors of Mortality for Critically III COVID-19 Patients: Systematic Review}

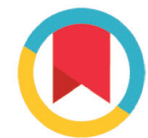

CrossMark

\author{
Lya Lusyana', Randika Rea Ariady², Gede Benny Setia Wirawan ${ }^{3 *}$
}

'Department of Anesthetics and Intensive Therapy, Sanjiwani Hospital, Gianyar, Indonesia;

${ }^{2}$ Anesthetics Department, Manambai Abdulkadir Hospital, Sumbawa, Indonesia;

${ }^{3}$ Center for Public Health Innovation, Faculty of Medicine, Udayana University, Denpasar, Indonesia;

*Corresponding author:

Gede Benny Setia Wirawan;

Center for Public Health Innovation, Faculty of Medicine, Udayana University, Denpasar, Bali, Indonesia;

benny.wirawan007@gmail.com

Received: 2021-03-04

Accepted: 2021-09-25

Published: 2021-10-27

\section{ABSTRACT}

Objective: To identify mortality predictors of critically ill COVID-19 patients in ICU based on current available literatures.

Methods: Systematic literature search was conducted in open-access databases. Data extraction was conducted for publication date, methodology employed, sample size, and results of multivariate analysis. Eligibility criteria for analysis was observational analytic design, sample size of 100 or more, and availability of multivariate results. Primary measures assessed was risk ratio, presented as odds ratio or hazard ratio. Data was analyzed qualitatively for themes that emerged for mortality predictors.

Results: Several mortality predictors were identified, which included demographic, clinical history, laboratory results, and oxygenation profile at ICU admission. Several of the most consistently reported mortality predictors was older age, one or more comorbidities that constitute metabolic syndrome, chronic pulmonary disorder, low lymphocyte and platelet count, elevated d-dimer, and low $\mathrm{PaO}_{2} / \mathrm{FiO}_{2}$ ratio.

Conclusions: Mortality predictors identified in this review were similar to previously known mortality and severity predictors of COVID-19 patients in general. This consistency may point to the potential of developing a scoring system to predict COVID-19 severity and mortality for clinical practice use.
Keywords: COVID-19, mortality predictors, critically ill, ICU, review.

Cite This Article: Lusyana, L., Ariady, R.R., Wirawan, G.B.S. 2021. Predictors of Mortality for Critically III COVID-19 Patients: Systematic Review. Intisari Sains Medis 12(3): 794-800. D0I: 10.15562/ism.v12i3.989

\section{INTRODUCTION}

As of January $5^{\text {th }} 2021$, WHO reported there has been a total of more than 83 million COVID-19 confirmed cases worldwide, along with 1.8 million mortalities. In South-East Asia region, which Indonesia is a part of, there has been 12 million confirmed cases and 184 thousand mortalities. ${ }^{1}$ In the same timeframe, Indonesia reported more than 770 thousand confirmed cases, with 23 thousand mortalities. ${ }^{2}$ This figures did not consider the possibility of underestimation due to inequality in healthcare access. ${ }^{3}$

Severity of COVID-19 has been a topic of discussion since its discovery. While there is a high proportion of asymptomatic cases, there has also been a high proportion of symptomatic, severe, and even critical case. An early report based on Chinese data found that around $80 \%$ of COVID-19 patients developed mild-to-moderate disease, $13.8 \%$ developed severe disease, while $6.1 \%$ developed critical disease. ${ }^{4}$ One later meta-analysis found higher severity profile with $32 \%$ intensive care unit (ICU) admission rate, suggesting critical disease, and $39 \%$ mortality rate of those in ICU. ${ }^{5}$

High ICU admission may be a strain to limited ICU resources available in various settings. An early projection for the situation in Bali, Indonesia projected that at peak of the pandemic there would be around 4 patients that need ICU beds for every 1 ICU bed available. ${ }^{6}$ In the course of the pandemic, ICU occupancy has fluctuated but remain fragile. In September, for example, ICU occupancy rate reach $75 \%$ in Jakarta.

In light of limited resource and increasing demand, prioritization is a must. One way to approach this issue as a clinical intensivist is to triage patients based on prognosis. ${ }^{8}$ To accomplish this, clinician must have a knowledge on prognosis predictors, including predictors for mortality, for specific population of COVID-19 patients in ICU.

There have been prior reviews on predictors of COVID-19 severity and ICU admission. Demographic, clinical history, and laboratory results has been identified as predictors of severity. Age over 55 years old and having multiple comorbidities has been identified as predictors of severity and/or mortality. Meanwhile, severe disease and mortality as also associated with hypoxia at admission and various laboratory abnormalities indicating coagulopathy and inflammation., ${ }^{9,10}$ However, there has been few literatures synthetizing currently known information on mortality predictors for critically ill COVID-19 patients in ICU. As such, this review is developed to encompass current knowledge on mortality predictors of COVID-19 patients in ICU.

\section{METHODS}

\section{Identification of literatures}

We conducted a review on open-access literatures on mortality predictors of COVID-19 patients in ICU. Literature searches was conducted on open-access scientific databases, including Pubmed, Europe PMC, and Google Scholar from 
November to December 2020. Keywords used included 'COVID-19', 'mortality predictors', 'ICU', and 'critically ill' with results limited to studies published since January $1^{\text {st }} 2020$.

Inclusion criteria for analysis was studies which employed observational analytic design written in English. Aforementioned observational analytics method included prospective and retrospective cohorts, as well as casecontrol studies. We excluded studies which employed experimental or clinical trial methods. We also excluded studies that have fewer than 100 observation subjects, did not report multivariate analysis

Table 1. PICOS for literature inclusion.

\begin{tabular}{ll}
\hline Population & COVID-19 patients admitted in ICU \\
Intervention & Not applicable \\
Comparison & Not applicable \\
Outcome & Mortality \\
Study design & Observational analytic with multivariate analysis \\
\hline
\end{tabular}

results, and studies with observation end-point other than mortality. These eligibility criteria were determined to limit review to most recent observational studies, which observe multiple potential predictors, with adequately large samples. PICOS breakdown for inclusion criteria can be seen in Table 1 .

\section{Quality appraisal}

Included studies was screened for quality appraisal before analysis. Quality appraisal was conducted using CASP (Critical Appraisal Skills Programme) Checklist for observational studies. The checklist included questions on research questions,

Table 2. Characteristics of included studies.

\begin{tabular}{|c|c|c|c|c|c|c|}
\hline No. & Author & Month, year & Title & Sample size & Mortality & Ref. \\
\hline 1 & Ayed et al. & November 2020 & $\begin{array}{l}\text { Assessment of clinical characteristics and } \\
\text { mortality-associated factors in COVID-19 } \\
\text { Critical cases in Kuwait }\end{array}$ & 103 & $57 \%$ & 11 \\
\hline 2 & Biran et al. & October 2020 & $\begin{array}{l}\text { Tocilizumab among patients with COVID-19 } \\
\text { in the intensive care unit: a multicentre } \\
\text { observational study }\end{array}$ & 764 & $45.6 \%$ & 12 \\
\hline 3 & Cummungs et al. & May 2020 & $\begin{array}{l}\text { Epidemiology, clinical course, and outcomes } \\
\text { of critically ill adults with COVID-19 in New } \\
\text { York City: a prospective cohort study }\end{array}$ & 257 & $39 \%$ & 13 \\
\hline 4 & Garcia et al. & July 2020 & $\begin{array}{l}\text { Prognostic factors associated with mortality } \\
\text { risk and disease progression in } 639 \text { critically } \\
\text { ill patients with COVID-19 in Europe: Initial } \\
\text { report of the international RISC-19-ICU } \\
\text { prospective observational cohort }\end{array}$ & 639 & $15.2 \%$ & 14 \\
\hline 5 & Grasselli et al. & July 2020 & $\begin{array}{l}\text { Risk Factors Associated With Mortality } \\
\text { Among Patients With COVID-19 in Intensive } \\
\text { Care Units in Lombardy, Italy }\end{array}$ & 3988 & $48.7 \%$ & 15 \\
\hline 6 & Gupta et al. & September 2020 & $\begin{array}{l}\text { Factors Associated With Death in Critically } \\
\text { Ill Patients With Coronavirus Disease } 2019 \text { in } \\
\text { the US }\end{array}$ & 2215 & $35.4 \%$ & 16 \\
\hline 7 & Haase et al. & August 2020 & $\begin{array}{l}\text { Characteristics, interventions, and longer- } \\
\text { term outcomes of COVID-19 ICU patients in } \\
\text { Denmark-A nationwide, observational study }\end{array}$ & 323 & $37 \%$ & 17 \\
\hline 8 & Lu et al. & July 2020 & $\begin{array}{l}\text { Continuously available ratio of } \mathrm{SpO} 2 / \mathrm{FiO} 2 \\
\text { serves as a noninvasive prognostic marker for } \\
\text { intensive care patients with COVID-19 }\end{array}$ & 280 & $40 \%$ & 18 \\
\hline 9 & $\mathrm{Xu}$ et al. & July 2020 & $\begin{array}{l}\text { Clinical course and predictors of } 60 \text {-day } \\
\text { mortality in } 239 \text { critically ill patients with } \\
\text { COVID-19: a multicenter retrospective study } \\
\text { from Wuhan, China }\end{array}$ & 239 & $61.5 \%$ & 19 \\
\hline
\end{tabular}

methodology, and analysis technique employed to assess validity of results.

\section{Data extraction, analysis, dan synthesis}

Data extraction was conducted using prepiloted forms by all authors independently. Extraction was conducted for publication date, study design, sample size, and results of multivariate analyses. Extraction results from each author was then matched to remove duplicate studies. Inclusion or exclusion of each study was discussed and agreed upon by all authors before effected.

Principal measures extracted from included studies was risk ratios for mortality based on multivariate results, which could be presented as odds ratio or hazard ratio depending on multivariate analyses employed by each study. Extracted data was analyzed qualitatively for themes that emerged. 


\section{RESULTS}

\section{Characterization of included literatures}

From initial literature screening in databases, we identified 97 articles which studied COVID-19 patients in ICU. After excluding duplicates, we are left with 47 articles. Further reading identified 18 articles with methodologies other than observational analytics, including descriptive studies and clinical trials, leaving 29 articles. Another 20 articles have fewer than 100 samples and observed endpoints other than mortality. In the end, we are left with 9 articles which satisfied inclusion and exclusion criteria to be analyzed.

Details of the included articles can be seen in Table 2. Of the 9 included articles, all were published in 2020. The earliest was published in May which amounted to two articles, while the latest was published in November. The majority of study was

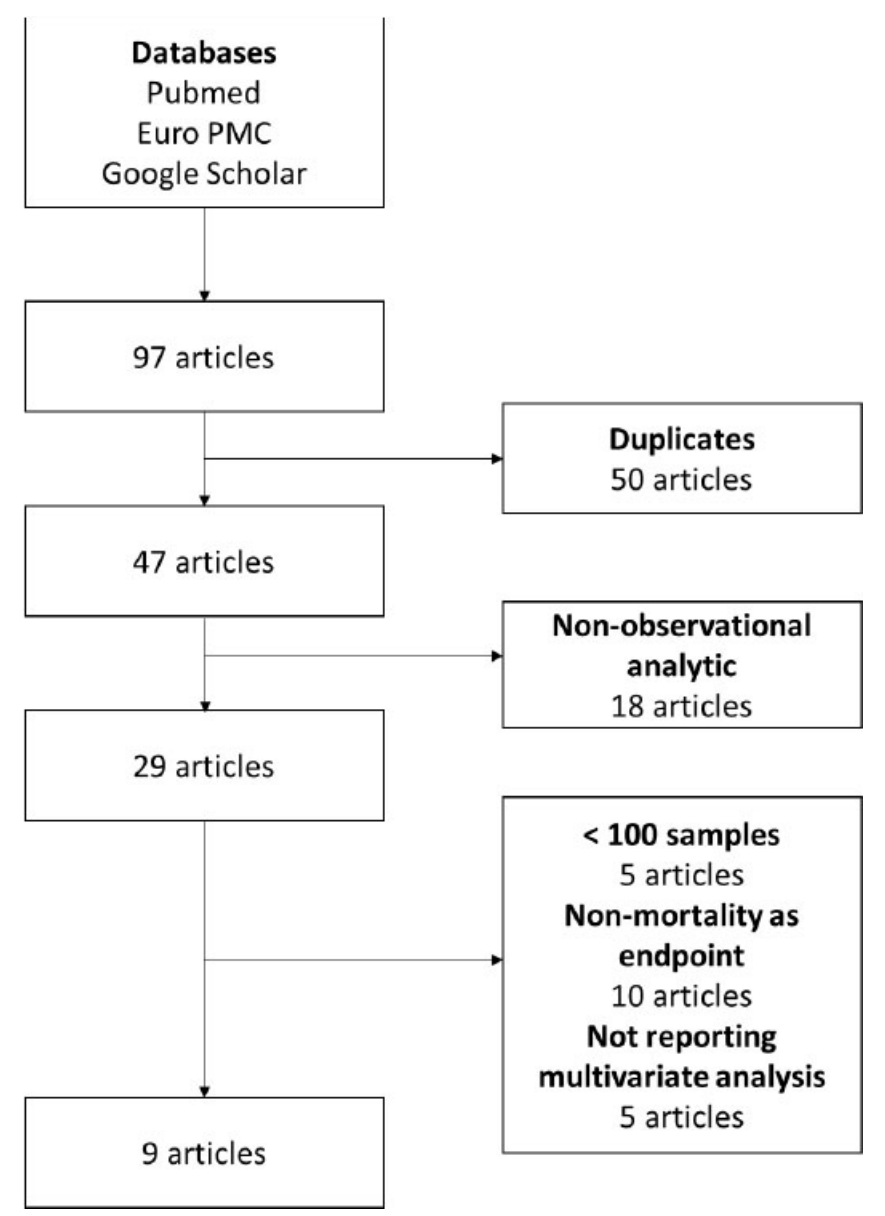

Figure 1. Literature selection process. recently published with 8 published in July 2020 or later. By methods, 5 studies reported cohort design with 4 being prospective cohorts and 1 retrospective cohorts. Meanwhile, 4 studies reported retrospective observational analytic design. Based on sample size, the smallest sample size was 103 samples while the largest was nearly 4000 samples.

From these articles we identified several categories of factors identified as predictors of mortality for COVID-19 patients in ICU. These categories included demographic, clinical history, clinical presentation, and laboratory results at admission. Some included studies also identified several medications that predicted mortalities, presenting their observational results in a fashion similar to quasi-non-random clinical trials.

Some articles identified prognostic factors by explicit bivariate and/or multivariate analyses with odds ratios (OR) or hazard ratios (HR) reported in the articles. Meanwhile, other articles only reported the potential correlation by mean difference analysis results (for numeric variables) or $\mathrm{p}$ value of cross-tabulation analyses without reporting the OR value. We attempted to report these results as is in the following tables.

There are wide variety of mortality rate reported by included studies. The lowest reported mortality rate was $15.2 \%$ in a study involving 639 subjects. The highest mortality was reported in a study which involve 239 subjects which reported $61.5 \%$ mortality. However, overall mortality reported was in $30 \%$ to $55 \%$ range with the median of $40 \%$ from all 9 included studies.

\section{Demographic and clinical history}

As much as 8 out of 9 included studies reported demographic and clinical history of the patient as independent predictors of mortality, as can be seen in Table 3. These predictors can be further categorized in to demographic, which included age and sex, and clinical history, which included patients' past diagnoses prior to ICU admission.

Several demographic factors have been repeatedly identified as mortality predictors in multiple studies. Older age is the most consistently identified mortality predictors with 5 out 8 studies that reported demographic factors reported older age as mortality predictor. ${ }^{12,13,16,17,19}$ The cutoff point reported differed between studies with one study reported added risk equal to hazard ratio of 1.3 (95\% CI 1.09 1.57) per 10 -year increment. ${ }^{13}$ The greatest increment mortality risk reported was between COVID-19 patient in ICU aged $\geq$ 80 years old compared to those aged $<40$ years old with OR of 11.15 (95\% CI 6.19 $-20.06){ }^{16}$

Another consistently reported mortality predictor was those related to metabolic syndrome. Hypertension, type 2 diabetes mellitus, hypercholesterolemia, and high body mass index (BMI) has been reported in multiple studies as mortality predictors for COVID-19 patients in ICU. Other predictors associated with mortality was ischemic heart disease and coronary heart disease, which themselves can be seen as complications of metabolic syndrome. As much as four included studies reported these factors as mortality 
Table 3. Demographic and clinical predictors of mortality.

\begin{tabular}{|c|c|c|c|c|}
\hline No. & Author & Predictors & OR/HR (95\%CI) & Ref. \\
\hline \multirow[t]{2}{*}{1} & Ayed et al. & Hypertension & $3.2(1.2-8.9)^{\mathrm{a}}$ & 11 \\
\hline & & Age ( $\geq 65$ yo) & $2.00(1.58-2.53)^{\mathrm{b}}$ & \\
\hline \multirow[t]{3}{*}{2} & Biran et al. & Sex (male) & $1.47(1.16-1.88)^{\mathrm{b}}$ & 12 \\
\hline & & Hypertension & $1.44(1.13-1.84)^{\mathrm{b}}$ & \\
\hline & & Age (per 10-year increment) & $1.30(1.09-1.57)^{\mathrm{b}}$ & \\
\hline \multirow[t]{2}{*}{3} & Cummings et al. & Chronic cardiac disease & $1.76(1.08-2.86)^{\mathrm{b}}$ & 13 \\
\hline & & COPD & $2.94(1.48-5.84)^{\mathrm{b}}$ & \\
\hline \multirow[t]{2}{*}{4} & Garcia et al. & Ischemic heart disease & $3.49(1.53-7.97)^{\mathrm{b}}$ & 14 \\
\hline & & Type 2 diabetes mellitus & $1.18(1.01-1.39)^{\mathrm{b}}$ & \\
\hline \multirow[t]{5}{*}{5} & Grasselli et al. & Hypercholesterolemia & $1.25(1.02-1.52)^{\mathrm{b}}$ & 15 \\
\hline & & COPD & $1.68(1.28-2.19)^{\mathrm{b}}$ & \\
\hline & & Age $(\geq 80$ yo v. $<40$ yo $)$ & $11.15(6.19-20.06) \mathrm{a}$ & \\
\hline & & Sex (male) & $1.5(1.19-1.90)^{\mathrm{a}}$ & \\
\hline & & $\mathrm{BMI}(>40 \mathrm{v} .<25)$ & $1.51(1.01-2.25)^{\mathrm{a}}$ & \\
\hline \multirow[t]{5}{*}{6} & Gupta et al. & Coronary artery disease & $1.47(1.07-2.02)^{\mathrm{a}}$ & 16 \\
\hline & & Active cancer & $2.15(1.35-3.43)^{\mathrm{a}}$ & \\
\hline & & Liver dysfunction & $2.61(1.30-5.25)^{\mathrm{a}}$ & \\
\hline & & Kidney dysfunction & $2.43(1.46-4.05)^{\mathrm{a}}$ & \\
\hline & & Age (70-79 yo v. 60-69) & $1.92(1.19-3.08)^{\mathrm{b}}$ & \\
\hline \multirow[t]{2}{*}{7} & Haase et al. & Age ( $\geq 80$ yo v. $60-69)$ & $2.77(1.55-4.96)^{\mathrm{b}}$ & 17 \\
\hline & & COPD & $1.86(1.23-2.35)^{\mathrm{b}}$ & \\
\hline 9 & Xu et al. & Age $\geq 65$ yo & $1.57(1.12-2.19)^{b}$ & 19 \\
\hline
\end{tabular}

${ }^{\text {a }}$ Reported as OR; ${ }^{\text {b }}$ Reported as HR

Table 4. Laboratory tests at ICU admission as predictors of mortality.

\begin{tabular}{|c|c|c|c|c|}
\hline No. & Author & Predictors & OR/HR $(95 \% \mathrm{CI})$ & Ref. \\
\hline \multirow{4}{*}{1} & \multirow{4}{*}{ Ayed et al. } & Albumin $(<22 \mathrm{~g} / \mathrm{L})$ & $7.5(2.1-26.2)^{a}$ & \multirow{4}{*}{11} \\
\hline & & Lymphocyte $\left(<0.5 \times 10^{9}\right.$ cells $\left./ \mathrm{L}\right)$ & $6.1(1.2-29.8)^{\mathrm{a}}$ & \\
\hline & & Procalcitonin $(>0.2 \mathrm{ng} / \mathrm{mL})$ & $3.8(1.3-7.8)^{\mathrm{a}}$ & \\
\hline & & D-dimer (> $1200 \mathrm{ng} / \mathrm{mL})$ & $5.1(1.2-21.6)^{a}$ & \\
\hline \multirow{3}{*}{3} & \multirow{2}{*}{ Cummings et al. } & Interleukin-6 (per decile increase) & $1.11(1.02-1.20)^{\mathrm{b}}$ & \multirow{2}{*}{13} \\
\hline & & D-dimer (per decile increase) & $1.10(1.01-1.19) b$ & \\
\hline & \multirow{3}{*}{ Garcia et al. } & D-dimer ( $\geq 1560 \mathrm{ng} / \mathrm{mL})$ & $2.25(1.33-3.83)^{\mathrm{b}}$ & \multirow{3}{*}{14} \\
\hline \multirow[t]{2}{*}{4} & & $\mathrm{LDH}(\geq 1.55 \mathrm{mmol} / \mathrm{L})$ & $5.04(1.51-16.67)^{\mathrm{b}}$ & \\
\hline & & Potassium $(\geq 4.16 \mathrm{mmol} / \mathrm{L})$ & $1.72(1.10-2.69)^{\mathrm{b}}$ & \\
\hline 9 & Xu et al. & Platelet count $\left(<125 \times 10^{9} / \mathrm{L}\right)$ & $2.01(1.39-2.91)^{\mathrm{b}}$ & 19 \\
\hline
\end{tabular}

${ }^{\text {a }}$ Reported as OR; ${ }^{\text {b }}$ Reported as HR

Table 5. Oxygenation profile as mortality predictors.

\begin{tabular}{|c|c|c|c|c|}
\hline No. & Author & Predictors & OR/HR $(95 \% \mathrm{CI})$ & Ref. \\
\hline 3 & Cummings et al. & $\mathrm{PaO}_{2} / \mathrm{FiO}_{2}$ ratio $(<206)$ & $11.11(1.37-100.00)^{b}$ & 13 \\
\hline 5 & Grasselli et al. & $\begin{array}{l}\mathrm{PaO}_{2} / \mathrm{FiO}_{2} \text { ratio (per } 100 \text { increment) } \\
\mathrm{PaO}_{2} / \mathrm{FiO}_{2} \text { ratio }(200-299 \text { v. w/out IMV) }\end{array}$ & $\begin{array}{l}1.25(1.15-1.35)^{\mathrm{b}} \\
1.72(1.13-2.63)^{\mathrm{a}}\end{array}$ & 15 \\
\hline 6 & Gupta et al. & $\begin{array}{l}\mathrm{PaO}_{2} / \mathrm{FiO}_{2} \text { ratio }(100-199 \text { v. w/out IMV }) \\
\mathrm{PaO}_{2} / \mathrm{FiO}_{2} \text { ratio }(<100 \mathrm{v} . \text { w/out IMV })\end{array}$ & $\begin{array}{l}2.13(1.58-2.87)^{\mathrm{a}} \\
2.94(2.11-4.08)^{\mathrm{a}}\end{array}$ & 16 \\
\hline
\end{tabular}

predictors. ${ }^{13-16}$

Other demographic and clinical predictors of mortality were less consistently reported. Three studies reported COPD as independent predictors of mortality. ${ }^{13,15,17}$ Meanwhile, one study reported male sex, active cancer, liver dysfunction, and kidney dysfunction as independent predictors of mortality. ${ }^{16}$

\section{Laboratory findings at admission}

Four included studies reported laboratory findings as mortality predictors for critically ill COVID-19 patients in ICU. These predictors can be broadly 
categorized as inflammation and coagulopathy indicators and can be seen in Table 4.

Inflammation indicators identified as mortality predictors included lymphocyte count, procalcitonin, interleukin-6 (IL6), and lactate dehydrogenase (LDH). Low lymphocyte count was reported by one study with cutoff point of $0.5 \times 10^{9}$ cells $/ \mathrm{L}^{11}$. This level is lower than lower reference range of lymphocyte count which usually stand at $1.0 \times 10^{9}$ cells $/ \mathrm{L}$. High procalcitonin, which usually indicate sepsis, IL-6, and LDH was also reported as mortality predictors by different studies. ${ }^{11,13,14}$

Coagulopathy markers has also been identified as mortality predictors, especially d-dimers which indicates thrombus formation. Three different included studies reported elevated d-dimers as mortality predictors for critically ill COVID-19 patients in ICU. ${ }^{11,13,14}$ However, the cutoff points presented by these studies differs. Cummings et al. presented an increased risk for mortality equal to $\mathrm{HR}$ of 1.10 (95\% CI 1.01 - 1.19) per decile increase without reporting a specific cutoff point. ${ }^{13}$ Meanwhile, Ayed et al. and Garcia et al. reported different cutoff points for mortality prediction, $>1200 \mathrm{ng} / \mathrm{mL}$ and $\geq$ $1560 \mathrm{ng} / \mathrm{mL}$ respectively. ${ }^{11,14}$ Low platelet count, which can indicate coagulopathy or inflammation was also reported as mortality predictor. ${ }^{19}$

Two laboratory results which did not fit into either aforementioned category was also identified as mortality predictors, namely albumin and potassium levels. ${ }^{11,14}$ These parameters were usually associated with organ failures, especially liver and kidney respectively.

\section{Oxygenation profile at admission}

$\mathrm{PaO}_{2} / \mathrm{FiO}_{2}$ ratio was identified as mortality predictors in four of the included studies. As can be seen in Table 5, three of these studies given different cutoff point of $\mathrm{PaO}_{2} / \mathrm{FiO}_{2}$ ratio for mortality prediction with the highest significant cutoff point was reported by Gupta et al. which reported $\mathrm{PaO}_{2} / \mathrm{FiO}_{2}$ ratio of $200-299$ to be associated with mortality with OR of 1.72 (95\% CI 1.13 - 2.63). ${ }^{16}$ Gupta et al. and Grasseli et al. also reported incremental increase of mortality risk with lower $\mathrm{PaO}_{2} /$ $\mathrm{FiO}_{2}$ ratio at admission. ${ }^{15,16}$

Another study also reported $\mathrm{PaO}_{2} / \mathrm{FiO}_{2}$ ratio as predictor of mortality for critically ill COVID-19 patients in ICU, although through longitudinal pattern analysis. Analyzing square root of $\mathrm{PaO}_{2} / \mathrm{FiO}_{2}$ ratio over time since admission, Lu et al. found lower $\mathrm{PaO}_{2} / \mathrm{FiO}_{2}$ ratio at admission among non-survivor which remained low when it was gradually increasing in survivor group. Multivariate Weibull relative risk model also identify this pattern as an independent mortality predictor. ${ }^{18}$

\section{DISCUSSION}

Our review included nine recently published observational analytic studies to identify mortality predictors among critically ill COVID-19 patients in ICU. Overall mortality reported ranged between $30 \%$ to $55 \%$ with median of $40 \%$. This reported mortality rate is much higher than overall infection fatality rate for COVID-19 which was reported to be around $1 \%{ }^{20}$ It is also much higher than overall in-hospital mortality of COVID-19 which was reported to be around $24 \%{ }^{21}$ The result identified several variables that predict mortality, which can be categorized into demographic, clinical history, laboratory findings, and oxygenation profiles.

Older age was among the most consistently reported independent mortality predictors in our review, although cutoff point differs between the studies. Comorbidity of diseases that constitute metabolic syndrome, including hypertension, type 2 diabetes mellitus, and obesity, has also been observed as independent mortality predictors. Heart disease, itself a complication of metabolic syndrome, has also been identified as independent mortality predictors.

Laboratory results that indicate severe inflammation and coagulopathy has also been identified as independent mortality predictors. This includes lymphocyte count, platelet count, procalcitonin, $\mathrm{LDH}$, and d-dimer. Other laboratory results indicating kidney and liver failure has also been identified as independent mortality predictors, namely potassium and albumin levels. Oxygenation, represented by $\mathrm{PaO}_{2} /$ $\mathrm{FiO}_{2}$ ratio, has also been consistently reported as mortality predictors.

These results did not differ significantly from previously identified risk factors for COVID-19 severity and mortality in general. Older age, hypertension, diabetes mellitus, and chronic pulmonary diseases has been identified as predictor of mortality in COVID-19 patients. Similarly, laboratory findings such as low platelet and lymphocyte count, low albumin, elevated creatinine, and d-dimer has also been identified as mortality predictors. $^{9,21}$

These findings are also in line with what is currently known of COVID-19 pathophysiological processes that lead to mortality. Severe inflammation and coagulopathy have been attributed to cause mortality in COVID-19 patients. Early in the pandemic, cytokine storm has been linked to severe COVID-19 cases and mortality. In this hypothesis, COVID-19 pathophysiology is understood as a hyperimmune syndrome, exemplified by extremely elevated cytokine markers (such as IL-6) and tissue damages (which leads to elevated procalcitonin and $\mathrm{LDH}){ }^{22,23}$ Others, however, has critiqued this hypothesis, pointing out low lymphocyte count often observed as severity and mortality predictor as evidence. ${ }^{24}$

This led us to the other hypothesized mortality pathway of COVID-19: coagulopathy. Evidence have piled up on the role of coagulopathy, especially thrombosis, play a role in COVID-19 pathophysiology. Arterial thrombosis has been observed in COVID-19 patients, especially among severe cases, with manifestations that included coronary heart syndrome, stroke, and microarterial thromboses such as pernio-like skin lesions. ${ }^{25,26}$ Indeed, meta-analysis has identified arterial thrombosis as one significant predictor of mortality for COVID-19 patients. $^{27}$

The clinical significance in identifying these mortality predictors is lies in clinical practice. While triage for ICU resources has been recommended early in the pandemic, current procedures for such triage was based on commonly employed semi-quantitative classifications, such as performance score and ASA score. ${ }^{28}$ This triage classification system put much burden on subjectivity of intensivist 
clinician, which would already be burdened by current load of COVID-19 patients. Indeed, Gupta et al. reported higher mortality risk for COVID-19 critically ill patients cared for in hospitals with fewer ICU beds available. ${ }^{16}$

One way to circumvent clinicians' subjectivityin this scenario is establishment of quantitative scoring system for triage. Shang et al. has devised a scoring system to predict mortality for severe COVID-19 cases dubbed COVID-19 Scoring System (CSS). It has potential use as triage classification system and utilized similar mortality predictors as identified in this review. ${ }^{29}$ However, it has not been widely adopted and its usefulness for critically ill patients in ICU setting remain to be studied further.

Per author's knowledge, this review is among the few to synthesize literatures on specific population of critically ill COVID-19 patients in ICU. However, it is not without its limitations. This review included relatively few studies. This is attributable to restrictive eligibility criteria in place, which include specific population, methodological employed, and sample size. Literature search was also only conducted on open-access databases which preclude many major databases. These limitations may cause some eligible literatures to be missed from the search process.

\section{CONCLUSIONS}

We identified observational analytic studies on mortality predictors of critically ill COVID-19 patients in ICU. The results identified several predictors, categorized into demographic, clinical history, laboratory results, and oxygenation at admission. Some of the most consistently reported independent mortality demographic and clinical history predictors was older age, metabolic syndrome, and chronic pulmonary disorder. Laboratory and oxygenation predictors included lymphocyte, d-dimer, and $\mathrm{PaO}_{2} / \mathrm{FiO}_{2}$ ratio. Identification of these mortality predictors could lead to quantitative scoring-based system for ICU resources triage process.

\section{ETHICAL CONSIDERATION}

Systematic reviews studies are exempt from reviews by Ethical Committee of Udayana University Medical Faculty/ Sanglah General Hospital.

\section{AUTHORS' CONTRIBUTIONS}

Conceptualization: LL, GBSW. Data curation: LL, RRA, GBSW. Formal analysis: GBSW.

Methodology: GBSW. Project administration: GBSW. Visualization: GBSW. Writing - original draft: LL. Writing - review \& editing: RRA, GBSW.

\section{CONFLICT OF INTEREST}

No potential conflict of interest relevant to this article was reported.

\section{FUNDING}

None.

\section{REFERENCE}

1. World Health Organization. COVID-19 Weekly Epidemiological Update. Geneva; 2021.

2. COVID-19 Response Acceleration Task Force. Distribution Maps (Indonesian) [Internet]. 2020 [cited 2021 Jan 31]. Available from: https://covid19.go.id/peta-sebaran

3. Wirawan GBS, Januraga PP. Correlation of Demographic, Health Care Availability, And COVID-19 Outcome: Indonesian Ecological Study. Front Public Heal. 2021;9(605290).

4. Verity R, Okell LC, Dorigatti I, Winskill $\mathrm{P}$, Whittaker $\mathrm{C}$, Imai $\mathrm{N}$, et al. Estimates of the severity of coronavirus disease 2019: a model-based analysis. Lancet Infect Dis. 2020;20(6):669-77.

5. Abate SM, Ali SA, Mantfardo B, Basu B. Rate of intensive care unit admission and outcomes among patients with coronavirus: A systematic review and Meta-analysis. PLoS One [Internet]. 2020;15(7 July):1-19. Available from: http:// dx.doi.org/10.1371/journal.pone.0235653

6. Wirawan A, Januraga PP. Forecasting COVID-19 Transmission and Healthcare Capacity in Bali, Indonesia. J Prev Med Public Heal. 2020;53(3):158-63.

7. Setiati S, Azwar MK. Dilemma of Prioritising Health and the Economy During COVID-19 Pandemic in Indonesia. Acta Med Indones. 2020;52(3):196-8.

8. Maves RC, Downar J, Dichter JR, Hick JL, Devereaux A, Geiling JA, et al. Triage of Scarce Critical Care Resources in COVID-19 An Implementation Guide for Regional Allocation: An Expert Panel Report of the Task Force for Mass Critical Care and the American College of Chest Physicians. Chest. 2020;158(1):212-25.
9. Mudatsir M, Wulandari L, Fajar JK, Soegiarto G, Ilmawan M, Purnamasari Y, et al. Predictors of COVID-19 severity: A systematic review and meta-analysis. F1000Research. 2020;9:1-24.

10. Gallo Marin B, Aghagoli G, Lavine K, Yang L, Siff EJ, Chiang SS, et al. Predictors of COVID-19 severity: A literature review. Rev Med Virol. 2020;(May).

11. Ayed M, Borahmah AA, Yazdani A, Sultan A, Mossad A, Rawdhan H. Assessment of clinical characteristics and mortality-associated factors in COVID-19 Critical cases in Kuwait. Med Princ Pract. 2020;

12. Biran N, Ip A, Ahn J, Go RC, Wang S, Mathura S, et al. Tocilizumab among patients with COVID-19 in the intensive care unit: a multicentre observational study. Lancet Rheumatol [Internet]. 2020;2(10):e603-12. Available from: http://dx.doi.org/10.1016/ S2665-9913(20)30277-0

13. Cummings MJ, Baldwin MR, Abrams D, Jacobson SD, Meyer BJ, Balough EM, et al. Epidemiology, clinical course, and outcomes of critically ill adults with COVID-19 in New York City: a prospective cohort study. Lancet [Internet]. 2020;395(10239):1763-70. Available from: http://dx.doi.org/10.1016/S01406736(20)31189-2

14. Wendel Garcia PD, Fumeaux T, Guerci P, Heuberger DM, Montomoli J, Roche-Campo F, et al. Prognostic factors associated with mortality risk and disease progression in 639 critically ill patients with COVID-19 in Europe: Initial report of the international RISC19-ICU prospective observational cohort. EClinicalMedicine [Internet]. 2020;25:100449. Available from: https://doi.org/10.1016/j. eclinm.2020.100449

15. Grasselli G, Greco M, Zanella A, Albano G, Antonelli M, Bellani G, et al. Risk Factors Associated with Mortality among Patients with COVID-19 in Intensive Care Units in Lombardy, Italy. JAMA Intern Med. 2020;180(10):1345-55.

16. Gupta S, Hayek SS, Wang W, Chan L, Mathews KS, Melamed ML, et al. Factors Associated with Death in Critically Ill Patients with Coronavirus Disease 2019 in the US. JAMA Intern Med. 2020;02115(11):1436-46.

17. Haase N, Plovsing R, Christensen S, Poulsen LM, Brøchner AC, Rasmussen BS, et al. Characteristics, interventions, and longer term outcomes of COVID-19 ICU patients in Denmark-A nationwide, observational study. Acta Anaesthesiol Scand. 2020;(August):1-8.

18. Lu X, Jiang L, Chen T, Wang Y, Zhang B, Hong $\mathrm{Y}$, et al. Continuously available ratio of $\mathrm{SpO} 2 /$ $\mathrm{FiO} 2$ serves as a noninvasive prognostic marker for intensive care patients with COVID-19. Respir Res. 2020;21(1):1-4.

19. Xu J, Yang X, Yang L, Zou X, Wang Y, Wu $Y$, et al. Clinical course and predictors of 60 day mortality in 239 critically ill patients with COVID-19: A multicenter retrospective study from Wuhan, China. Crit Care. 2020;24(1):111. 
20. Meyerowitz-Katz G, Merone L. A systematic review and meta-analysis of published research data on COVID-19 infection fatality rates. Int J Infect Dis [Internet]. 2020;101:138-48. Available from: https://doi.org/10.1016/j. ijid.2020.09.1464

21. Mesas AE, Cavero-Redondo I, Álvarez-Bueno C, Cabrera MAS, de Andrade SM, SequíDominguez I, et al. Predictors of in-hospital COVID-19 mortality: A comprehensive systematic review and meta-analysis exploring differences by age, sex and health conditions. PLoS One. 2020;15(11 November):1-23.

22. Castelli V, Cimini A, Ferri C. Cytokine Storm in COVID-19: "When You Come Out of the Storm, You Won't Be the Same Person Who Walked in." Vol. 11, Frontiers in Immunology. 2020.

23. de la Rica R, Borges M, Gonzalez-Freire M. COVID-19: In the Eye of the Cytokine Storm. Vol. 11, Frontiers in Immunology. 2020.
24. Riva G, Nasillo V, Tagliafico E, Trenti T, Comoli P, Luppi M. COVID-19: More than a cytokine storm. Crit Care. 2020;24(1):10-2.

25. Price LC, McCabe C, Garfield B, Wort SJ. Thrombosis and COVID-19 pneumonia: The clot thickens! Eur Respir J. 2020;56(1).

26. Freeman EE, McMahon DE, Lipoff JB, Rosenbach M, Kovarik C, Takeshita J, et al. Pernio-like skin lesions associated with COVID-19: A case series of 318 patients from 8 countries. J Am Acad Dermatol. 2020;83(2):486-92.

27. Malas MB, Naazie IN, Elsayed N, Mathlouthi A, Marmor R, Clary B. Thromboembolism risk of COVID-19 is high and associated with a higher risk of mortality: A systematic review and meta-analysis. EClinicalMedicine [Internet]. 2020;29-30:100639. Available from: https://doi. org/10.1016/j.eclinm.2020.100639
28. Sprung CL, Joynt GM, Christian MD, Truog RD, Rello J, Nates JL. Adult ICU Triage during the Coronavirus Disease 2019 Pandemic: Who Will Live and Who Will Die? Recommendations to Improve Survival*. Crit Care Med. 2020;48(8):1196-202.

29. Shang Y, Liu T, Wei Y, Li J, Shao L, Liu $M$, et al. Scoring systems for predicting mortality for severe patients with COVID-19. EClinicalMedicine [Internet]. 2020;24(December 2019):100426. Available from: https://doi.org/10.1016/j. eclinm.2020.100426

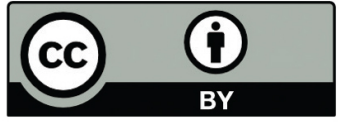

This work is licensed under a Creative Commons Attribution 